\title{
PERANCANGAN DAN ANALISIS SISTEM ALAT UKUR ARUS LISTRIK MENGGUNAKAN SENSOR ACS712 BERBASIS ARDUINO UNO DENGAN STANDARD CLAMPMETER
}

\author{
Trias Prima Satya \\ Sekolah Vokasi, Departemen Teknik Elektro dan Informatika \\ Universitas Gadjah Mada \\ E-mail: trias.primasatya@ugm.ac.id \\ Fitri Puspasari \\ Sekolah Vokasi, Departemen Teknik Elektro dan Informatika \\ Universitas Gadjah Mada \\ Hristina Prisyanti \\ Sekolah Vokasi, Departemen Teknik Elektro dan Informatika \\ Universitas Gadjah Mada \\ Elisabeth Ruthma Meilani Saragih \\ Sekolah Vokasi, Departemen Teknik Elektro dan Informatika \\ Universitas Gadjah Mada
}

\begin{abstract}
ABSTRAK
Telah dilakukan penelitian tentang perancangan sistem alat pengukur arus menggunakan sensor ACS712 berbasis arduino uno. Penelitian ini bertujuan untuk merancang, membuat dan menguji karakteristik alat pengukur arus listrik dengan sensor ACS712. Metode yang digunakan dalam penelitian ini yaitu metode perbandingan langsung dengan clamp meter standar. Pengambilan data dilakukan menggunakan beban 3 lampu yang berbeda, dengan jeda pengambilan data setiap 7 detik. Hasil yang diperoleh dalam penelitian ini menunjukkan bahwa, pada lampu 1 diperoleh hasil ukur alat uji $(3,62 \pm$ 0,04)A, clamp meter standar (3 \pm 0 ) A dengan error sebesar 0,7 A dan ketidakpastian relatif sebesar 24,83 $\%$. Lampu 2 diperoleh hasil ukur alat uji $(3,41 \pm 0,03) \mathrm{A}$, clamp meter standard $(3 \pm 0)$ A dengan nilai error sebesar 0,41 A dan ketidakpastian relatif sebesar 14,14\%. Sedangkan pada lampu 3 diperoleh hasil ukur alat uji $(3,49 \pm 0,03$ ), clamp meter standard ( $3 \pm 0$ ) A dengan nilai error sebesar 0,6 A dan ketidakpastian relatif sebesar $20,34 \%$.
\end{abstract}

Kata kunci: clamp meter; acs 712; arduino; arus listrik.

\section{ABSTRACT}

The research of designing electric current instrument measurement system using ACS712 sensor based on Arduino Uno has been done. The aims of this research was design, assembly, and characteristic test of instrument of electric current instrument by ACS712 sensor. The method used in this research was direct comparison by standard clamp meter. Data retrieval was done using the load of 3 different lamps by data retrieval pauses every 7 seconds. The result of this research show that lamp 1has instrument test result $(3,62 \pm 0,04) \mathrm{A}$, standard clamp meter $(3 \pm 0) \mathrm{A}$, error value $0,7 \mathrm{~A}$ and relative uncertainty 24,83 $\%$. Lamp 2 has instrument test result $(3,41 \pm 0,03) \mathrm{A}$, standard clamp meter $(3 \pm 0)$ A, error value $0,41 \mathrm{~A}$ and relative uncertainty $14,14 \%$. Then, lamp 3 has instrument test result $(3,49 \pm 0,03)$, standard clamp meter $(3 \pm 0) A$, error value $0,41 \mathrm{~A}$ and relative uncertainty $20,34 \%$.

Keywords: clamp meter; acs 712; arduino, electric current.

\section{PENDAHULUAN}

Arus listrik merupakan energi yang dapat disalurkan melalui penghantar berupa kabel. Arus listrik ini timbul karena adanya perubahan muatan yang pindah melewati suatu titik per muatan waktu dalam suatu konduktor listrik [1]. Dalam kehidupan manusia arus listrik memiliki peran yang sangat penting. Penggunaan energi listrik ini telah menjadi hal yang mutlak seiring dengan perkembangan teknologi elektronika [2]. Arus listrik sendiri dibagi menjadi dua jenis yaitu arus DC (direct current) dan AC (alternating current) [3]. Untuk mendeteksi arus listrik tersebut diperlukan sensor arus yang merupakan 
suatu sensor dengan kemampuan memantau penggunaan arus listrik dan dapat memberikan nilai analog sehingga penggunaan tenaga listrik dapat dikontrol dan diatur [4]. Salah satu sensor untuk proses deteksi arus listrik tersebut adalah ACS712 yang bekerja dengan prinsip efek Hall. Sensor ACS 712 ini,(Gambar 1), merupakan salah satu sensor yang mampu mendeteksi arus AC atau DC. Sensor ACS712 memiliki nilai akurasi yang lebih tinggi, linearitas yang lebih baik, dipasok oleh $5 \mathrm{~V}$ DC; tegangan output adalah $4.5 \mathrm{~V}$, dan perlu lebih sedikit rangkaian untuk pengolahan data [5].

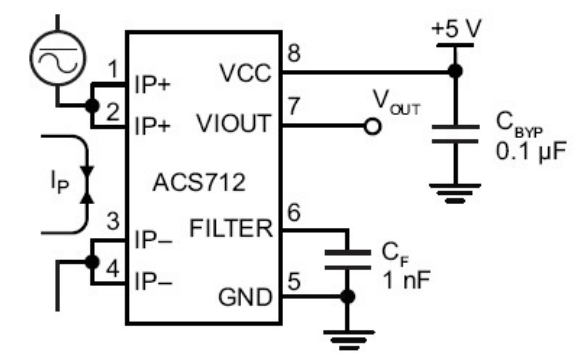

Gambar 1. Kaki-Kaki Sensor Arus ACS712 [5]

Sensor ini bekerja dengan memanfaatkan peristiwa hall effect yang bekerja menggunakan prinsip gaya Lorenz. Sensor ini juga memiliki tegangan kerja $5 \mathrm{~V}$ dan memiliki resistansi internal sebesar 1.2 $\mathrm{m} \Omega$. Bagian-bagian dari sensor arus ACS712 yaitu:

Pin $1:$ IP+ yang merupakan masukan arus.

Pin $2:$ IP+ yang merupakan masukan arus Pin

Pin 3 : IP- yang merupakan keluaran arus

Pin 4 : IP- yang merupakan keluaran arus

Pin 5 : Ground

Pin 6 : Terminal untuk kapasitor eksternal

Pin 7 : Keluaran tegangan analog

Pin 8 : Power supply $5 \mathrm{~V}$

Sensor arus ACS 712 tersebut dibuat secara compact oleh pabrik dalam bentuk IC yang bekerja dengan prinsip merespon dan mengukur medan magnet yang timbul disekitar kawat berarus dengan mengkombinasikan fungsi resistor shun dan current transformer sebagai sensor arus AC maupun DC yang memiliki tingkat akurasi pembacaan yang tinggi [6].

Arduino uno (Gambar 2) merupakan board sistem mikrokontroler yang bersifat yang open source. Arduino UNO didasarkan pada mikrokontroler ATmega328P. Papan diprogram dengan Arduino IDE dilengkapi dengan 14 pin input / output (I / O). Tegangan catu daya disediakan melalui kabel USB atau catu daya eksternal dengan tegangan kisaran 7-20 volt [7]

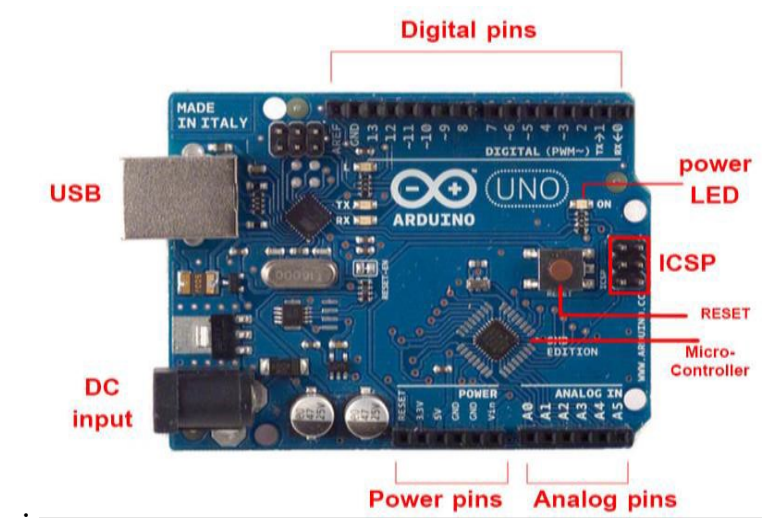

Gambar 2. Arduino Uno [7]

Jenis alat pengukur arus listrik salah satunya adalah tang ampare atau Clamp meter yaitu alat yang berfungsi untuk mengukur besarnya arus listrik baik DC maupun AC dalam rentang yang luas bahkan sampai 2000A. Clamp meter saat ini dengan transduser efek Hall dapat beroperasi dalam arus DC atau arus AC pada frekuensi hingga $100 \mathrm{kHz}$. Tingkat keakuratan Clamp meter mencapai $1 \%$ hingga $2 \%$ dari rentang pengukuran. Kinerja dari Clamp meter dipengaruhi oleh beberapa faktor diantaranya faktor posisi dan kondisi lingkungan [8]. 


\section{METODOLOGI PENELITIAN}

Alat dan bahan yang digunakan adalah laptop, arduino kit, sensor ACS712, lampu, kabel, dan Clamp Meter sebagaimana yang ditunjukkan oleh Gambar 3. Penelitian dimulai dengan mempersiapkan alat-alat yang digunakan. Pengukuran dilakukan dengan menginstall aplikasi Poteus 8.6 dan Arduino di laptop. Kemudian membuat rancangan rangkaian dengan proteus (Gambar 4), dan dilanjutkan membuat program untuk mengoperasikan rangkaian tersebut. Setelah itu rangkaian yang ada diproteus disimulasikan dengan arduino kit dan project board. Analisis data dilakukan dengn mengidentifikasi perbedaan arus terukur antara Clamp Meter sebagai instrumen standard dengan sistem yang dibuat (sensor ACS 712 berbasis Arduino uno).

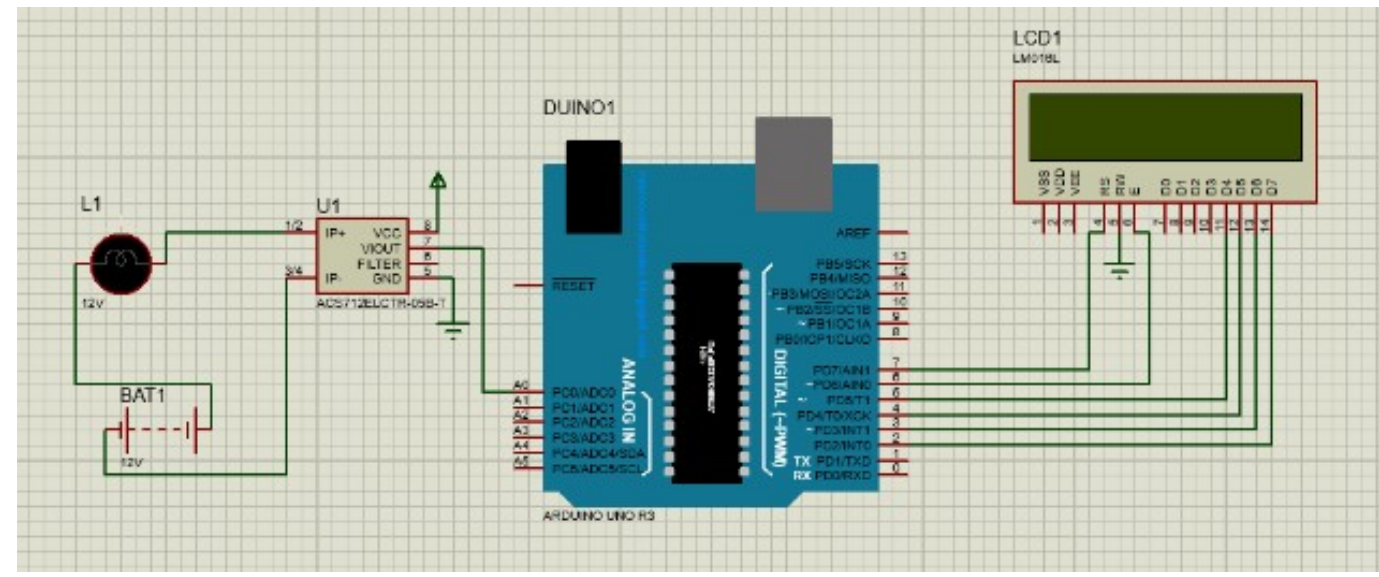

Gambar 3. Skema Rangkaian Alat

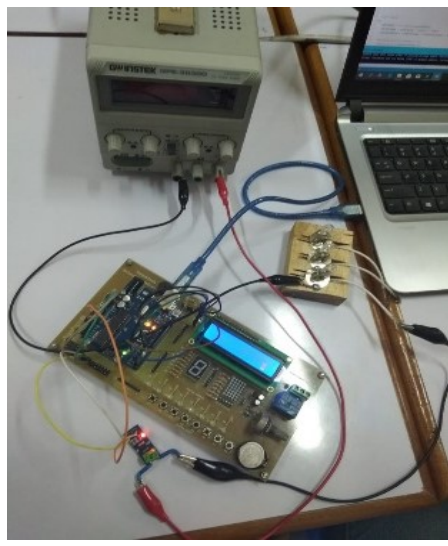

Gambar 4. Rangkaian Hardware

Proses running program dan akuisisi data pada arduino dilakukuan sepeti pada diagram alir (Gambar 5). Alir diagram menggambarkan Arduino Uno sebagai pusat pengolahan data yang berasal dari sensor. Setelah data diterima maka akan dikirim ke PC melalui serial monitor. Berikut adalah alir diagram dari perangkat lunak untuk memunculkan nilai arus listrik melalui serial monitor: 


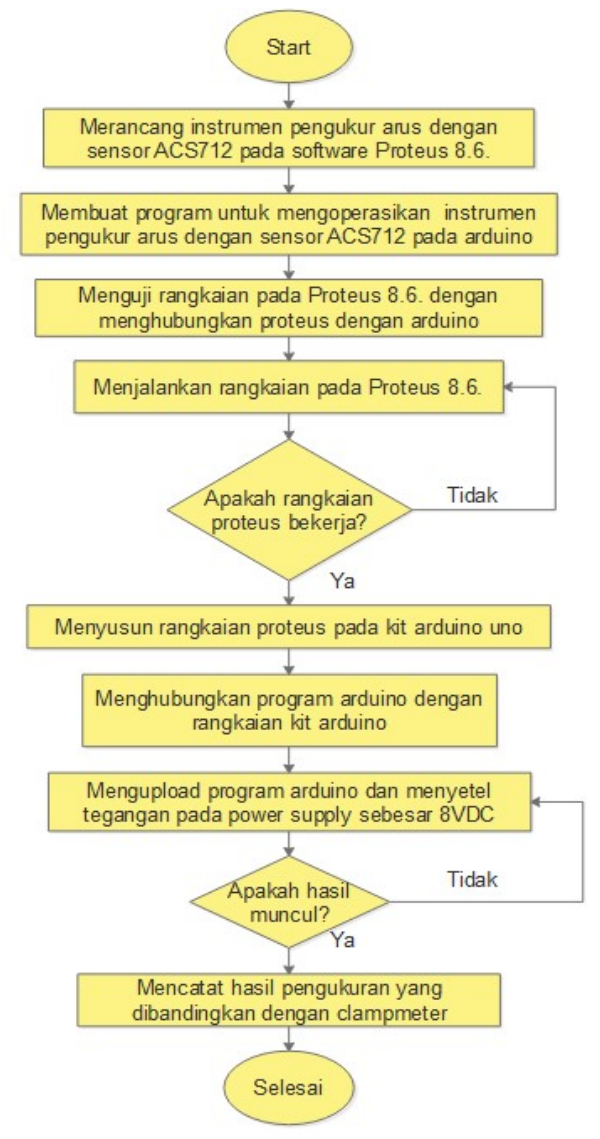

Gambar 5. Diagram Alir Pengujian

\subsection{Pengujian dan Analisis}

Untuk mengetahui perbandingan antara alat uji dan alat standar dalam pengukuran suhu dan kelembaban udara ini, dapat dilakukan dengan perhitungan yang dituliskan secara sistematis sebagai berikut :

a. Rata - rata

$$
\bar{x}=\frac{x_{1}+x_{2}+x_{3}+x_{n}}{n}
$$

b. Standar deviasi

$$
S D=\sqrt{\frac{\sum\left(\bar{x}-x_{i}\right)^{2}}{n-1}}
$$

c. Nilai error

$$
\text { Error }=\mid \mathrm{Uji}-\text { Standar } \mid
$$

d. Ketidakpaastian relatif

$$
K R=\frac{U j i-\text { standard }}{\text { Standard }} \times 100 \%
$$

\section{HASIL DAN PEMBAHASAN}

Pada penelitian ini, proses pengambilan data menggunakan 3 variasi beban 3 lampu yaitu lampu 1, lampu 2 dan lampu 3. Pada setiap variasi beban lampu diambil sebanyak 10 data dalam waktu 50 detik, 
sehingga dalam 5 detik diperoleh 1 data. Pengambilan data dilakukan dengan menggunakan tegangan power supply sebesar $12 \mathrm{~V}$. Hasil yang diperoleh kemudian di tampilkan pada dua buah instrument, yaitu LCD $16 \times 2$ atau serial monitor yang terhubung ke arduino IDE, dan pada display Clamp meter standar digital yang nilainya juga termonitor pada $D C$ power supply yang digunakan. Rata-rata hasil pengujian ditunjukkan oleh tabel 1 berikut :

Tabel 1. Rata-rata hasil Pengujian alat ukur arus listrik menggunakan sensor ACS712 dengan beban 3 buah lampu yang berbeda

\begin{tabular}{|c|c|c|c|c|c|c|}
\hline & \multirow{2}{*}{$\begin{array}{c}\text { Tegangan } \\
\text { (V) }\end{array}$} & \multicolumn{3}{|c|}{ Arus Listrik (A) } & \multirow{2}{*}{$\begin{array}{l}\text { Kesalahan } \\
\text { Relatif (\%) }\end{array}$} & \multirow{2}{*}{$\begin{array}{l}\text { Error Arus } \\
\text { Listrik }(A)\end{array}$} \\
\hline & & $U j i$ & Standard & Power Suplay & & \\
\hline Lampu 1 & 12 & 3,62 & 2,90 & 3,21 & 24,83 & 0,72 \\
\hline Lampu 2 & 12 & 3,70 & 2,80 & 3,21 & 32,14 & 0,90 \\
\hline Lampu 3 & 12 & 3,49 & 2,90 & 3,25 & 20,34 & 0,59 \\
\hline
\end{tabular}

Perbandingan nilai fluktuasi antara instrumen standar (clamp meter) dengan instrument yang diuji (sensor arus ACS712 berbasis Arduino uno) pada 10 kali pengujian dengan beban lampu ditunjukan pada gambar 6 berikut. (Warna kuning menunjukkan pembacaan instrumen yang diuji dan warna biru menunjukkan nilai instrumen standar)

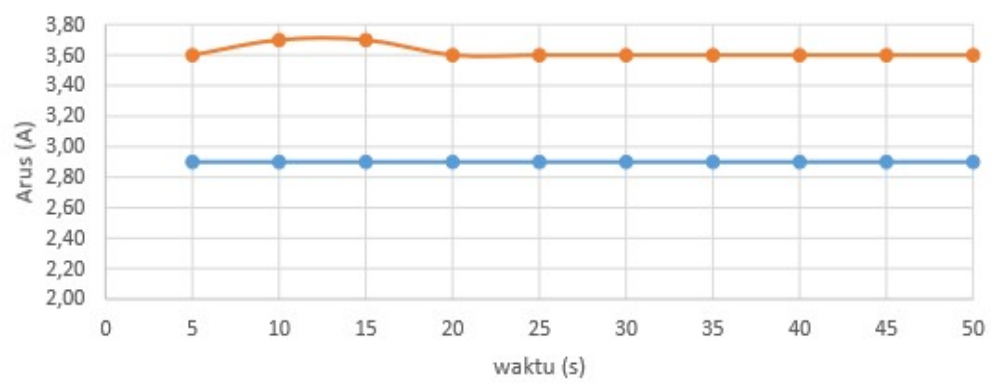

(a)

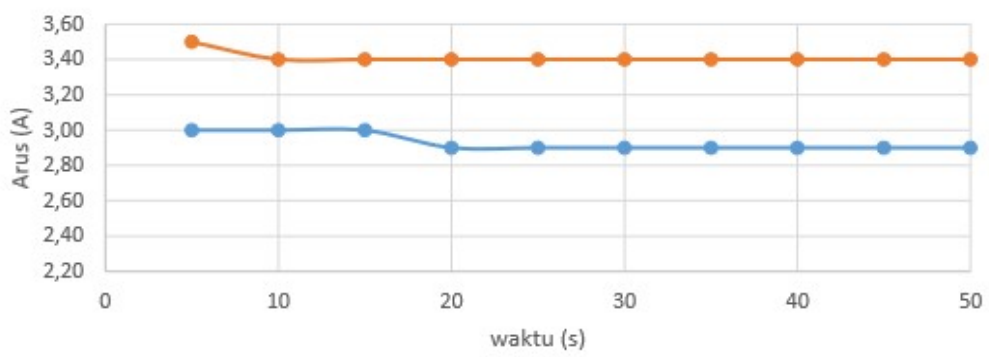

(b)

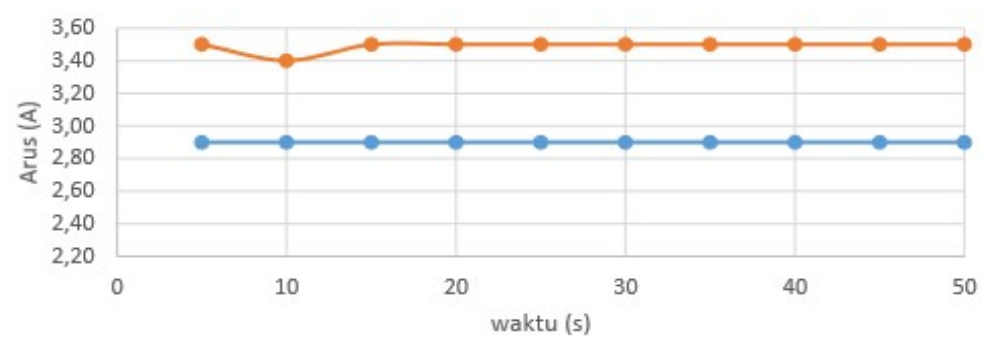

(c)

\section{Gambar 6. Grafik Hubungan Antara Waktu (S) dengan Arus (a) Uji Dan Standard Pada (a) Lampu 1 Pengujian (b) Lampu 2 Pengujian dan (c) Lampu 3 Pengujian}

Hasil data yang diperoleh pada variasi lampu 1 berdasarkan tabel 1 pada alat ukur uji sebesar $(3,62 \pm$ 0,04)A sedangkan pada clamp meter standar sebesar $(3 \pm 0$ ) A dengan error sebesar $0,7 \mathrm{~A}$ dan ketidakpastian relatif sebesar 24,83\%. Untuk lampu 2 sebesar $(3,41 \pm 0,03)$ A sedangkan pada clamp meter 
standar $(3,31 \pm 0,03)$ A dan $(3 \pm 0)$ A dengan nilai error sebesar 0,41 A dan ketidakpastian relatif sebesar 14,14\%. Pada lampu 3 diperoleh hasil uji sebesar $(3,49 \pm 0,03)$ A, sedangkan pada clamp meter standar sebesar ( $3 \pm 0$ ) A dengan error sebesar 0,6 A dan ketidakpastian relatif sebesar 20,34\%. Nilai error adalah perbedaan diantara nilai terukur pada instrumen yang uji dengan nilai pada instrumen standar yang telah diketahui nilai benarnya [9]. Sehingga dalam penggunaan sensor tersebut harus ditambahkan koreksi sebesar -0,7 A (lampu 1), -0,41 (lampu 2), dan -0,6 (lampu 3).

Dari grafik pada gambar 6 , diketahui bahwa pembacaan clamp meter memiliki stabilitas pembacaan yang baik pada rentang waktu 0 - 50 sekon. Namun demikian, pada sensor ACS712, menunjukkan bahwa terjadi fluktuasi arus listrik dari waktu $0-20$ sekon, dan akan stabil setelahnya. Berdasarkan hasil yang diperoleh, disimpulkan bahwa perancangan alat ukur berupa clamp meter ini memiliki ketidakpastian relatif diatas 5\%. Artinya nilai yang diperoleh dari alat uji masih jauh clamp meter standarnya. Nilai ketidakpastian relatif yang paling tinggi yaitu pada variasi lampu 1 dengan nilai $24,83 \%$ sedangkan nilai ketidakpastian relatif yang paling rendah di peroleh pada variasi lampu 3 yaitu sebesar 20,34 \%. Ketidakpastian relatif merupakan ketidakpastian yang dibandingkan dengan hasil ukurnya [10]. Besarnya nilai ketidakpastian relatif yang didapat dikarenakan jarak antara beban dan sensor terlalu jauh, dan juga coding program pada arduino yang menghasilkan selisih nilai yang berbeda dengan standarnya. Pada pengukuran arus ini digunakan lampu yang berfungsi sebagai beban untuk menghalangi arus yang cukup besar. Hal ini bertujuan untuk pengaman sistem dari korsleting yang dapat membahayakan sistem yang dibuat jika tidak dipasang beban.

\section{KESIMPULAN}

a. Alat ukur arus dibuat dengan sensor ACS 712 di peroleh nilai ketidakpastian relatif lebih dari 5\%.

b. Pengukuran pada variasi lampu 1 berdasarkan tabel 1 pada alat ukur uji sebesar $(3,62 \pm 0,04) \mathrm{A}$ sedangkan pada clamp meter standar sebesar ( $3 \pm 0$ ) A dengan error sebesar 0,7 A dan ketidakpastian relatif sebesar 24,83\%. Untuk lampu 2 sebesar $(3,41 \pm 0,03)$ A sedangkan pada clamp meter standar $(3,31 \pm 0,03)$ A dan $(3 \pm 0)$ A dengan nilai error sebesar 0,41 A ketidakpastian relatif sebesar $14,14 \%$, dan pada lampu 3 diperoleh hasil uji sebesar $(3,49 \pm 0,03)$ A sedangkan pada clamp meter standar sebesar ( $3 \pm 0$ ) A dengan error sebesar 0,6 A dan ketidakpastian relatif sebesar 20,34 \%.

c. Besarnya nilai ketidakpastian relatif yang didapat dikarenakan jarak antara beban dan sensor terlalu jauh, dan juga coding pada arduino yang menghasilkan nilai yang berbeda dengan nilai standarnya.

\section{DAFTAR PUSTAKA}

[1] A. Fauzi, "Penentuan Konduktivitas Dan Resistivitas Air Laut Dengan Pengukuran Tidak Langsung," J. Material. dan Pendidikan Fisika., pp. 37-41.

[2] M. Mario, Boni P. Lapanporo, "Rancang Bangun Sistem Proteksi dan Monitoring Penggunaan Daya Listrik Pada Beban Skala Rumah Tangga Berbasis Mikrokontroler ATMega328P," Prisma Fiika., vol. VI, no. 01, pp. 26-33, 2018.

[3] M. P. S.N. Hutagalung, "Pembelajaran Fisika Dasar Dan Elektronika Dasar (Arus, Hambatan Dan Tegangan Listrik) Menggunakan Aplikasi Matlab Metode Simulink ," J. Ikat. Alumni Fis. Univ. Negeri Medan, vol. 4, no. 2, pp. 2-5, 2018.

[4] R. A. Dalimunthe, "Pemantau Arus Listrik Berbasis Alarm Dengan Sensor Arus," Seminar Nasional Royal., pp. 333-338, 2018.

[5] L. Li, Y. Chen, H. Zhou, H. Ma, and J. Liu, "The application of hall sensors ACS712 in the protection circuit of controller for humanoid robots," 2010 Int. Conf. Comput. Appl. Syst. Model. (ICCASM 2010), vol. 12, 2010.

[6] R. F. C. M.J. Mnati, A. Van den Bossche, "A Smart Voltage and Current Monitoring System for Three Phase Inverters Using an Android," Sensors, vol. 17, no. 4, p. 872, 2017.

[7] L. . Abdulrazzak, I.A., Bierk, H., Aday, "Humidity and temperature monitoring," Int. J. Eng. Technol., vol. 7, no. 4, pp. 5174-5177, 2018.

[8] F. Galliana and P. P. Capra, "Traceable Technique to Calibrate Clamp Meters in AC Current From 100 to 1500 A," no. September, 2012.

[9] S. V. Gupta, Measurement Uncertainties Physical Parameters and Calibration of Instruments. Springer Heidelberg Dordrecht London New York, 2012.

[10] T. Kristiantoro, N. Idayanti, N. Sudrajat, A. Septiani, and M. Dedi, "Ketidakpastian Pengukuran pada Karakteristik Material Magnet Permanen dengan Alat Ukur Permagraph Measurement Uncertainty on The Characteristic of Permanent Magnetic Materials by Permagraph Instrument," J. Elektron. dan Telekomunikasi., vol. 16, no. 1, pp. 1-6, 2016. 